\title{
High Performance Liquid Chromatographic Determination of Acetoacetate by Post-Column Derivatization with $p$-Nitrobenzene Diazonium Fluoroborate
}

\author{
Susumu Yamato, ${ }^{*, a}$ Kiyomi Kobayashi, ${ }^{a}$ Keiko Ebara, ${ }^{a}$ Kenji Shimada, ${ }^{a}$ and Shin Ohta ${ }^{b}$ \\ ${ }^{a}$ Department of Analytical Chemistry, Faculty of Pharmaceutical Sciences, Niigata University of Pharmacy and Applied \\ Life Sciences; 5-13-2 Kamishin'ei-cho, Niigata 950-2081, Japan: and ${ }^{b}$ Department of Pharmacy, Nagano Red Cross \\ Hospital; 5-22-1 Wakasato, Nagano 380-8582, Japan. $\quad$ Received October 18, 2002; accepted January 16, 2003
}

\begin{abstract}
We have applied a color-developing reagent, $p$-nitrobenzene diazonium fluoroborate (diazo reagent) as a post-column derivatization tool for the specific determination of acetoacetate (AcAc) in high performance liquid chromatography (HPLC). A mobile phase consisting of $50 \mathrm{~mm}_{\mathrm{KH}_{2}} \mathrm{PO}_{4}, 4 \mathrm{~mm}$ tetra-n-butylammonium phosphate (TBAP) as an ion-pair reagent and $2 \mathrm{v} / \mathrm{v} \%$ methanol, $\mathrm{pH} 3.5$, diazo reagent solution with $0.2 \%$ triton $\mathrm{X}$ 100, and alkaline solution of $1.5 \mathrm{~mol} / \mathrm{l} \mathrm{NaOH}$ were pumped using three independent pumps. Specific color development on-line was monitored at $645 \mathrm{~nm}$. A calibration curve for AcAc standard solution with an injection volume of $20 \mu$ showed a good linearity in the range $0.01-2.5 \mathrm{~mm}$ with a correlation coefficient of 0.999 . For the determination of 3-hydroxybutyrate (3-HOBA), 3-HOBA was converted to AcAc by an enzymatic-coupling method using 3-HOBA dehydrogenase and lactate dehydrogenase. Analytical recoveries of AcAc and 3-HOBA added to serum and urine were satisfactory.
\end{abstract}

Key words acetoacetate; diazo reagent; high performance liquid chromatography (HPLC); 3-hydroxybutyrate; ketone body

The accurate determination of the ketone body ratio (3-hydroxybutyrate (3-HOBA)/acetoacetate (AcAc)) is important in the diagnosis of diabetes mellitus and of other metabolic disorders. For this purpose, several methods for the determination of the ketone bodies (AcAc, acetone and 3-HOBA) have been reported. These procedures are based on the enzymatic method of Williamson et al. ${ }^{1)}$ and are classified either as fluorimetric, ${ }^{2,3)}$ radiochemical ${ }^{4)}$ or gas chromatographic methods. ${ }^{5,6)}$

Harano et al. developed a highly sensitive and simplified spectrophotometric method for the differential determination of ketone bodies. ${ }^{7)}$ They used $p$-nitrobenzene diazonium fluoroborate (diazo reagent) as a color-developing reagent. AcAc was reacted with a diazo reagent to form a hydrazo compound. The hydrazo compound was then converted to the azo derivative using alkali, which gave a characteristic strong absorption at $645 \mathrm{~nm}$. 3-HOBA was enzymatically converted to AcAc and then measured by this method.

Unfortunately, the diazo reagent lacks the required specificity for certain clinical applications. Diazo reagent reacts with activated methylene and at the $o$ - or $p$-positions of phenolic compounds. Consequently the diazo reagent can react with compounds such as oxaloacetate (OxAc), anti diabetes mellitus drugs and other drugs in current medical usage. Since urine is relatively rich in OxAc, this method is not suitable for the assay of urine samples. In this case, the introduction of derivatization techniques in liquid chromatography may improve the detection property and selectivity of the assay.

In this paper, we have applied the diazo reagent as a postcolumn derivatization tool for the specific determination of AcAc in high performance liquid chromatography (HPLC).

\section{MATERIALS AND METHODS}

Lithium acetoacetate (AcAc), $\beta$-nicotinamide adenine dinucleotide $(\beta$-NAD), 3-hydroxybutyrate dehydrogenase (3-
HOBADH) from Rhodopseudomonas spheroids (type II, suspension in $3.2 \mathrm{M}$ ammonium sulfate solution, $\mathrm{pH} 6.0,8.2$ units/mg protein) and L-lactic dehydrogenase (LDH) from rabbit muscle (type II, suspension in $3.2 \mathrm{M}$ ammonium sulfate solution, $\mathrm{pH} 6.0,1150$ units $/ \mathrm{mg}$ protein) were purchased from Sigma (St. Louis, MO, U.S.A.). DL-3-Hydroxybutyrate sodium salt (3-HOBA), oxalacetic acid, sodium pyruvate, polyoxyethylene octylphenylether (Triton X-100) and control serum I were obtained from Wako (Osaka, Japan). $p$-Nitrobenzenediazonium tetrafluoroborate were obtained from Tokyo Kasei (Tokyo, Japan). Quantitative urine control normal (1) was purchased from Bio-Rad Laboratories (Irvine, CA, U.S.A.). The ion-pair reagent, tetra- $n$-butylammonium phosphate (TBAP), was obtained from Nacalai Tesque (Kyoto, Japan). Other reagents were of analytical-reagent grade.

Spectrophotometric Assay of AcAc Spectrophotometric determination of AcAc was carried out according to the procedure reported by Harano et al. ${ }^{7)}$ with a slight modification. In brief, a standard solution of AcAc and a solution with or without other drugs in a total volume of $0.5 \mathrm{ml}$ were mixed with $0.5 \mathrm{ml}$ of $0.4 \mathrm{M}$ citrate buffer, $\mathrm{pH} 3.5$, and then $0.5 \mathrm{ml}$ of diazo reagent solution $(1.8 \mathrm{mg} / \mathrm{ml})$. The mixture was kept at $37^{\circ} \mathrm{C}$ for $10 \mathrm{~min}$, and then $0.5 \mathrm{ml}$ of $1.5 \mathrm{M} \mathrm{NaOH}$ solution containing $0.2 \mathrm{v} / \mathrm{v} \%$ Triton X-100, non-ionic detergent, was added. After incubation at room temperature for 5 min, color development was measured at $645 \mathrm{~nm}$.

Sample Preparation for the Assay of AcAc in Serum and Urine For the determination of AcAc in serum and urine by HPLC, sample preparation was carried out as follows. A defined amount of AcAc was dissolved in the control serum or control urine, and a $0.5 \mathrm{ml}$ aliquot was transferred to a test tube. The sample solution was deproteinized with $0.05 \mathrm{ml}$ of $6 \mathrm{M}$ perchloric acid (PCA), and then the mixture was centrifuged at $1500 \boldsymbol{g}$ for $10 \mathrm{~min}$. An aliquot of supernatant $(0.4 \mathrm{ml})$ was neutralized with $0.1 \mathrm{ml}$ of $2.5 \mathrm{M} \mathrm{NaOH}$. The neutralized sample was filtered through a $0.45 \mu \mathrm{m}$ pore 


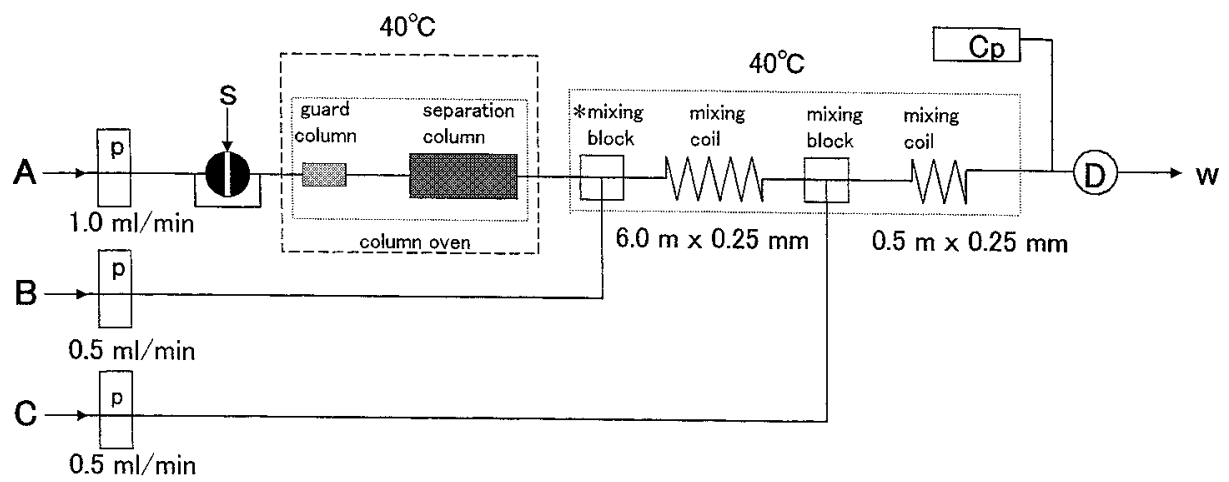

Fig. 1. Schematic Diagram of the Post-Column Reaction Detection System for the Determination of AcAc

Pump $\mathrm{A}=$ mobile phase $\left(50 \mathrm{~mm} \mathrm{KH}_{2} \mathrm{PO}_{4}, 4 \mathrm{~mm}\right.$ TBAP and $2 \mathrm{v} / \mathrm{v} \%$ methanol, $\mathrm{pH} 3.5$ ); pump $\mathrm{B}=$ diazo reagent solution (diazo reagent, $1.8 \mathrm{mg} / \mathrm{ml}$ and $0.2 \mathrm{v} / \mathrm{v} \%$ Triton $\mathrm{X}-100$ ); pump $\mathrm{C}=1.5 \mathrm{M} \mathrm{NaOH}$ solution; $\mathrm{S}=$ sample injector; $\mathrm{D}=$ detector; $\mathrm{Cp}=$ computing integrator; $\mathrm{W}=$ waste.

size filter (Millipore Corp., Bedford, MA, U.S.A.). A $20 \mu 1$ aliquot of filtrate was injected into the HPLC.

Enzymatic Conversion of 3-HOBA to AcAc For the determination of 3-HOBA, $0.3 \mathrm{ml}$ of control serum or control urine containing 3-HOBA was incubated with $0.1 \mathrm{ml}$ of an enzyme reagent cocktail, which consists of $5 \mathrm{ml}$ of $50 \mathrm{~mm}$ sodium phosphate buffer, $\mathrm{pH} 8.0,2 \mathrm{ml}$ of 3-HOBADH (32 $\mathrm{kU} / \mathrm{l}), 1 \mathrm{ml}$ of $\mathrm{LDH}\left(6.7 \times 10^{3} \mathrm{kU} / \mathrm{l}\right), 1 \mathrm{ml}$ of $10 \mathrm{~mm} \beta$-NAD and $1 \mathrm{ml}$ of $0.1 \mathrm{M}$ sodium pyruvate. The mixture was incubated at $37^{\circ} \mathrm{C}$ for $10 \mathrm{~min}$ and the reaction was then terminated by adding $0.05 \mathrm{ml}$ of $6 \mathrm{M} \mathrm{PCA}$, and $0.1 \mathrm{ml}$ of water. The mixture was then centrifuged, neutralized and filtered as described above.

HPLC Condition and Post-Column Reaction Detection System A schematic diagram of the post-column reaction detection system for the determination of AcAc is shown in Fig. 1. The mobile phase comprised of $50 \mathrm{mM} \mathrm{KH}_{2} \mathrm{PO}_{4}, 4 \mathrm{~mm}$ TBAP as an ion-pair reagent and $2 \mathrm{v} / \mathrm{v} \%$ methanol, $\mathrm{pH} 3.5$, pumped by Shimadzu LC-10AD pump (Kyoto, Japan) at a flow-rate of $1.0 \mathrm{ml} / \mathrm{min}$. The sample solution $(20 \mu \mathrm{l})$ was injected through a Rheodyne Model 7125 injector (Cotati, CA, U.S.A.), and was chromatographed on a separation column of Capcell Pak $\mathrm{C}_{18}(150 \mathrm{~mm} \times 6 \mathrm{~mm}$ I.D., SG type, $5-\mu \mathrm{m}$ particle;, Shiseido, Tokyo, Japan), fitted with a TSK guardgel ODS-80Ts $(15 \times 3.2 \mathrm{~mm}$ I.D., Tosoh, Tokyo, Japan $)$. The separation column was thermostated at $40^{\circ} \mathrm{C}$ in a column oven (CTO-10AS, Shimadzu). The effluent from the column was reacted with a solution of a color-developing reagent, diazo reagent solution, which comprised of $p$-nitrobenzene diazonium fluoroborate (diazo reagent, $1.8 \mathrm{mg} / \mathrm{ml}$ ) and $0.2 \mathrm{v} / \mathrm{v} \%$ Triton X-100. Diazo reagent solution was pumped by another Shimadzu LC-10AD pump at a flow-rate of $0.5 \mathrm{ml} / \mathrm{min}$. The reaction was carried out in a volume of $650 \mu \mathrm{l}$ in a mixing block with particle beads, and then in a mixing coil $(6.0 \mathrm{~m} \times$ $0.25 \mathrm{~mm}$ I.D.). The reaction mixture was then converted to an azo compound using alkali $(1.5 \mathrm{~m} \mathrm{NaOH}$ solution), which was pumped by Shimadzu LC-10Ai pump at a flow-rate of $0.5 \mathrm{ml} / \mathrm{min}$. The color development after mixing with another mixing coil $(1.5 \mathrm{~m} \times 0.25 \mathrm{~mm}$ I.D. $)$ was quantified at $645 \mathrm{~nm}$ using a spectrophotometer (SPD-6AV, Shimadzu) equipped with an $8 \mu$ l flow cell. The mixing block and two mixing coils were thermostated at $40^{\circ} \mathrm{C}$ by circulating hot water.
Table 1. Maximum Wavelength and Molar Absorptivity of Typical Compounds Reacted with Diazo Reagent

\begin{tabular}{|c|c|c|c|}
\hline & $\lambda_{\max }(\mathrm{nm})$ & $\varepsilon$ at $\lambda_{\max }$ & $\varepsilon$ at $645 \mathrm{~nm}$ \\
\hline Acetoacetate (AcAc) & 645 & 49000 & 49000 \\
\hline Acetone & 641 & 395 & 394 \\
\hline Oxaloacetate (OxAc) & 645 & 22000 & 22000 \\
\hline Creatinine & 410 & 2000 & 250 \\
\hline Xanthurenic acid & 554 & 18000 & 8700 \\
\hline Bamethane sulfate & 489 & 19000 & 430 \\
\hline Etilefrin hydrochloride & 504 & 15000 & 230 \\
\hline Mefenamic acid & 508 & 320 & 270 \\
\hline Insulin & 486 & 24000 & 780 \\
\hline Acarbose & \multicolumn{2}{|c|}{ N.R. } & \\
\hline Metformin hydrochloride & \multicolumn{2}{|c|}{ N.R. } & \\
\hline
\end{tabular}

N.R.: Not reacted.

\section{RESULTS AND DISCUSSION}

Reaction of Several Compounds with Diazo Reagent Compounds with an active methylene or phenolic ring were reacted with diazo reagent and the color was allowed to develop. Diazo reagent was used to treat biological materials, adrenergic agents, antipyretic analgesics and antidiabetics. Maximum wavelength and the molar absorptivity of typical compounds are shown in Table 1 . The molar absorptivity of the azo derivative of AcAc at $645 \mathrm{~nm}$ was 1.5 -fold higher than that reported by Harano et al. ${ }^{7)}$ In the report, Triton X100 was added in citrate buffer, whereas we have found that the addition of Triton X-100 in alkaline solution increased the color development. OxAc, xanthurenic acid, bamethane sulfate, etilefrin hydrochloride and insulin were all reacted with diazo reagent. However, with the exception of OxAc, the maximum absorption wavelength was different from the azo derivative of AcAc. Nevertheless the absorbance at 645 $\mathrm{nm}$ was not negligible. Effects of these compounds on the color development of AcAc are shown in Table 2. These compounds gave either a positive or negative error.

Separation of AcAc from Interference Compounds Reversed-phase ion-pair chromatography is a useful technique for the analysis of polar ionized solutes. ${ }^{8,9}$ Optimum $\mathrm{pH}$ of the reaction of AcAc with diazo reagent to form the hydrazo compound is known to be around $\mathrm{pH} 3.5$. From the different $\mathrm{p} K_{\mathrm{a}}$-values of $\mathrm{AcAc}\left(\mathrm{p} K_{\mathrm{a}}=3.62\right)$ and $\operatorname{OxAc}\left(\mathrm{p} K_{\mathrm{a} 1}=\right.$ 2.55, $\left.\mathrm{p} K_{\mathrm{a} 2}=4.37\right), A c A c$ and OxAc would be expected to 
separate at $\mathrm{pH} 3.5$, using TBAP as a counter ion. The effect of TBAP concentration, methanol concentration and $\mathrm{pH}$ on color development are shown in Fig. 2. The effect of TBAP in the mobile phase on the capacity factor $\left(k^{\prime}\right)$ was also investigated (Fig. 2). From the results, $50 \mathrm{~mm} \mathrm{KH}_{2} \mathrm{PO}_{4}, 4 \mathrm{~mm}$ TBAP as an ion-pair reagent and $2 \mathrm{v} / \mathrm{v} \%$ methanol, $\mathrm{pH} 3.5$, was expected to be a convenient mobile phase. In this postcolumn reaction detection system for the determination of AcAc, we have designed a stable supply of diazo reagent. Diazo reagent was not stable in solution, so it was dissolved in $0.2 \mathrm{v} / \mathrm{v} \%$ Triton X-100, non-ionic detergent, and pumped into the stream. Using this method, a stable supply of diazo reagent solution over a $24 \mathrm{~h}$ period was achieved. Consequently, AcAc was separated from OxAc and other interference compounds (see Fig. 3).

Calibration Curve for the Determination of AcAc The quantitative response was obtained by injecting samples containing various amounts of AcAc standard. The plot of peak area versus the concentration of AcAc was linear in the range

Table 2. Effects of Compounds on the Color Development

\begin{tabular}{llc}
\hline \hline \multicolumn{1}{c}{ Compound } & $\mathrm{mm}^{a)}$ & Relative absorbance (\%) \\
\hline Acetoacetate (AcAc) & 0.03 & 100 \\
In the presence & 3.27 & 117.7 \\
Acetone & 0.03 & 147.6 \\
Oxaloacetate (OxAc) & 89.8 \\
Creatinine & 1.20 & 130.9 \\
Xanthurenic acid & 0.06 & 79.9 \\
Bamethane sulfate & 0.06 & 98.6 \\
Etilefrin hydrochloride & 0.06 & 97.8 \\
Mefenamic acid & 0.06 & 105.4 \\
Insulin & 0.05 & \\
\hline
\end{tabular}

a) The values were expressed as a concentration in the final assay mixture.
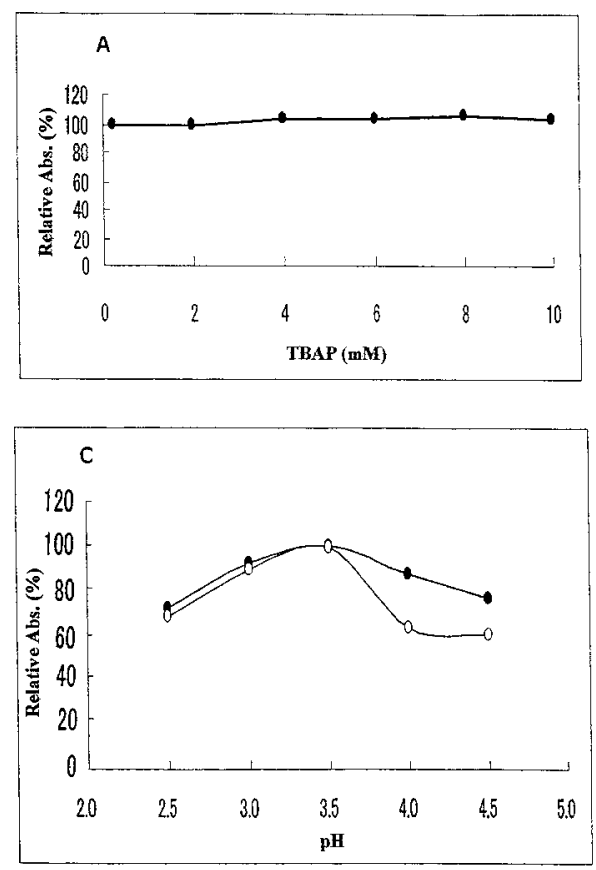

$0.01-2.5 \mathrm{~mm}$, which is adequate for clinical use. The regression equation and the correlation coefficient $(r)$ for peak area $(y, \mathrm{~V} \mathrm{~s})$ versus concentration $(x, \mathrm{~mm})$ were $y=7.054 x+0.066$, $r=0.999(n=11)$. The detection limit at a signal-to-noise ratio of 3 was $3 \mu \mathrm{m}$.

Application to Serum and Urine Figure 4 shows chromatograms of AcAc spiked into control serum and control urine. AcAc was clearly detected in the chromatograms. An-

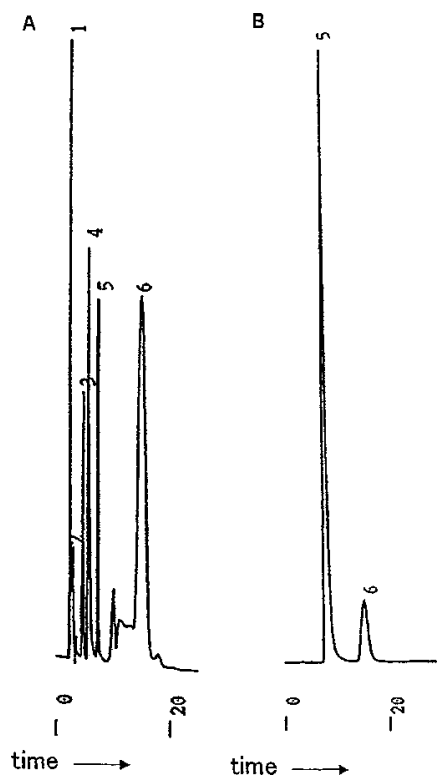

Fig. 3. Chromatograms of (1) Creatinine, (2) Etilefrin Hydrochloride, (3) Bamethane Sulfate, (4) Acetone, (5) AcAc and (6) OxAc

(A) Ultra-violet absorption at $245 \mathrm{~nm}$ and (B) visible absorption at $645 \mathrm{~nm}$. For UV detection, distilled water instead of the color-developing reagent and alkali solution was pumped by pump $\mathrm{B}$ and $\mathrm{C}$ at a flow-rate of $0.5 \mathrm{ml} / \mathrm{min}$.
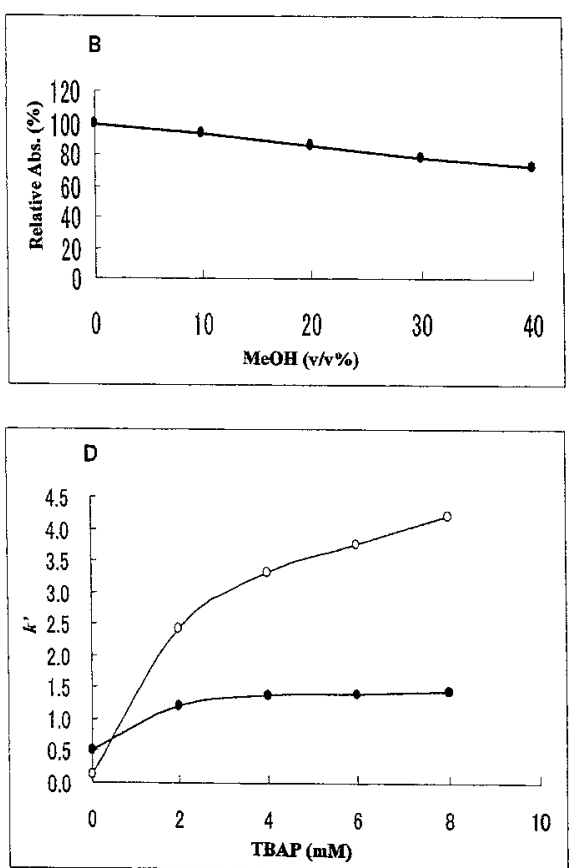

Fig. 2. (A) Effect of TBAP Concentration, (B) Methanol Concentration, (C) $\mathrm{pH}$ on the Color Development, and (D) Effect of the Concentration of TBAP in the Mobile Phase on the Capacity Factor $\left(k^{\prime}\right)$

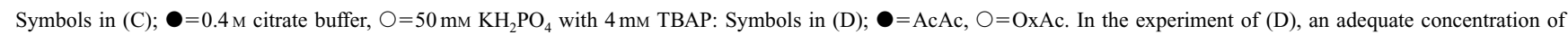
TBAP was added to the mobile phase containing $50 \mathrm{~mm} \mathrm{KH}_{2} \mathrm{PO}_{4}$ and $2 \mathrm{v} / \mathrm{v} \%$ methanol, and a pH was adjusted to 3.5 with $5 \%$ orthophosphoric acid $\left(\mathrm{H}_{3} \mathrm{PO} \mathrm{O}_{4}\right.$. Separation column: Capcell Pak $\mathrm{C}_{18}(150 \mathrm{~mm} \times 6 \mathrm{~mm}$ I.D.), Detection: $245 \mathrm{~nm}$. 

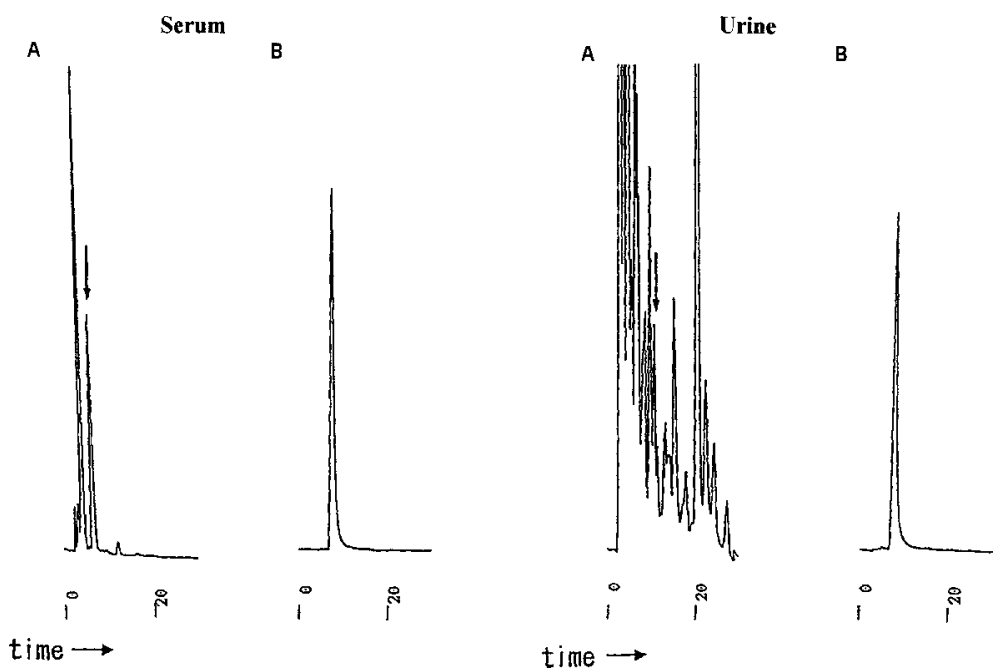

Fig. 4. Chromatograms of AcAc Detection in Control Serum and Control Urine

(A) Ultra-violet absorption at $245 \mathrm{~nm}$ and (B) visible absorption at $645 \mathrm{~nm}$. The detection was the same as described in the legend of Fig. 3. The control serum and control urine were both spiked with $0.5 \mathrm{~mm}$ AcAc. The arrows indicate the AcAc peak.

Table 3. Recovery of AcAc and/or 3-HOBA added to Control Serum and Urine

\begin{tabular}{|c|c|c|c|c|c|c|}
\hline \multirow{2}{*}{ Sample } & \multirow{2}{*}{ Compound } & \multirow{2}{*}{ Added (mм) } & \multirow{2}{*}{ Found (mм) } & \multirow{2}{*}{ Recovery (\%) } & \multicolumn{2}{|c|}{ Ratio (3-HOBA/AcAc) } \\
\hline & & & & & Theoretical & Practical \\
\hline \multirow[t]{7}{*}{ Serum } & Acetoacetate (AcAc) & 0.05 & 0.052 & 103.8 & & \\
\hline & & 0.25 & 0.249 & 99.7 & & \\
\hline & & 0.5 & 0.473 & 94.6 & & \\
\hline & & 2.5 & 2.415 & 96.6 & & \\
\hline & 3-Hydroxybutyrate (3-HOBA) & 1.25 & 1.164 & 93.1 & & \\
\hline & $\operatorname{AcAc}(0.5 \mathrm{~mm})$ & 0.5 & 0.478 & 95.6 & & \\
\hline & +3-HOBA (1.25 mM) & 1.25 & 1.271 & 101.7 & 2.50 & 2.66 \\
\hline \multirow[t]{7}{*}{ Urine } & Acetoacetate (AcAc) & 0.05 & 0.059 & 118.0 & & \\
\hline & & 0.25 & 0.267 & 106.8 & & \\
\hline & & 0.5 & 0.488 & 97.6 & & \\
\hline & & 2.5 & 2.455 & 98.2 & & \\
\hline & 3-Hydroxybutyrate (3-HOBA) & 1.25 & 1.225 & 98.0 & & \\
\hline & AcAc $(0.5 \mathrm{~mm})$ & 0.5 & 0.491 & 98.2 & & \\
\hline & +3-HOBA (1.25 mм) & 1.25 & 1.113 & 89.0 & 2.50 & 2.27 \\
\hline
\end{tabular}

alytical recoveries of AcAc and OxAc added to control serum and control urine are shown in Table 3. Different AcAc concentrations ranging from 0.05 to $1.25 \mathrm{~mm}$ and/or $1.25 \mathrm{~mm} 3$-HOBA were added to control serum or control urine. For the determination of 3-HOBA, enzymatic conversion of 3-HOBA to AcAc was carried out before HPLC injection. The content of the D-form in commercial DL-3HOBA was estimated to be approximately $40 \%$. The relative standard deviation (RSD) of the within-day precision with $0.3 \mathrm{~mm}$ AcAc in serum and with $0.25 \mathrm{~mm} \mathrm{AcAc}$ in urine was $1.7 \%(n=10)$ and $4.6 \%(n=10)$, respectively. The percentage of the recoveries was satisfactory. Concentrations of 3HOBA and AcAc and the ketone body ratio (3-HOBA/ $\mathrm{AcAc}$ ) in serum and urine from a healthy volunteer were obtained $0.044 \mathrm{~mm}$ (3-HOBA), $0.047 \mathrm{~mm}$ (AcAc) and 0.94 (ratio) for serum, and $0.083 \mathrm{~mm}$ (3-HOBA), $0.071 \mathrm{~mm}$ (AcAc) and 1.17 (ratio) for urine, respectively. The proposed method can be used for the accurate determination of the ketone body ratio (3-HOBA/AcAc) as an alternative way, without any interference by OxAc, especially in urine, and other drugs administered to patients. The specific determination of
AcAc in biological samples as described in this paper has great potential in several clinical applications.

\section{REFERENCES}

1) Williamson D. H., Mellanby J., Krebs H. A., Biochem. J., 82, 90-96 (1962).

2) Antonis A., Clark M., Pilkington T. R. E., J. Lab. \& Clin. Med., 68, 340-356 (1966).

3) Young D. A. B., Renold A. E., Clin. Chim. Acta, 13, $791-793$ (1966).

4) Ogihara M., Tokumitsu Y., Ui M., Anal. Biochem., 85, 387—400 (1978).

5) Kimura M., Kobayashi K., Matsuoka A., Hayashi K., Kimura Y., Clin. Chem., 31, 596-598 (1985).

6) Kimura M., Ogasahara N., Kobayashi K., Hitoi A., Matsuoka A., Kimura Y., Clin. Chem., 36, 160-161 (1990).

7) Harano Y., Kosugi K., Hyosu T., Uno S., Ichikawa Y., Shigeta Y., Clin. Chim. Acta, 134, 327-336 (1983).

8) "Ion-pair Chromatography: Theory and Biological and Pharmaceutical Applications," ed. by Hearn M. T. W., Chromatographic Science Series, Vol. 31, Dekker, New York, 1985.

9) Yamato S., Wakabayashi H., Nakajima M., Shimada K., J. Chromatogr. B, 656, 29-35 (1994). 